\title{
DEIONIZAÇÃO CAPACITIVA PARA PROMOVER A DEMOCRATIZAÇÃO DO ACESSO À ÁGUA POTÁVEL
}

Capacitive deionization to promote democratization of access to potable water

Desionización capacitiva para promover la democratización del acceso al agua potable

Eueliton Marcelino Coelho Junior

Graduando em Ciência da Computação, USP, Brasil eueliton.coelho@usp.br

Luís Fernando Quintino Doutorando em Eng. Elétrica e da Computação, UNICAMP, Brasil. luis.quintino@outlook.com

César Augusto Della Piazza Doutor em Eng. Da Produção, UNIMEP, Brasil. della_piazza@yahoo.com.br 


\section{RESUMO}

O presente artigo elucidou a importância da dessalinização de água como método de abastecimento de municípios pobres e famílias em vulnerabilidade social. Ficou evidenciado que a preservação dos recursos hídricos, por diversas ações, é intensamente debatida na sociedade atual. Elencamos diversas medidas que versam sobre o reúso da agua, técnicas de preservação hídrica ou mesmo estratégias e equipamentos que permitem a extração de água doce dos oceanos. Verificamos que a dessalinização é uma solução amplamente estudada por viabilizar o tratamento de águas salobras ou salinas, possibilitando a produção de água potável. Identificamos a existência e desenvolvimento de equipamentos que operam em qualquer escala, com custos, benefícios e impactos ambientais variáveis, conforme a técnica empregada. Efetuamos o comparativo entre a osmose reversa, um método que é utilizado em larga escala por diversos países, e a deionização capacitiva, que está em fase crescente de pesquisas em todo mundo. Comprovamos que há necessidade de amplificação dos estudos sobre a deionização capacitiva para possibilitar o desenvolvimento de equipamentos que permitam dessalinizar águas para promover o desenvolvimento de regiões pobres, a saúde dessas populações e famílias, democratizando o acesso à água.

PALAVRAS-CHAVE: Dessalinização de água. Deionização capacitiva. Osmose Reversa.

\section{ABSTRACT}

This papers elucidated the importance of water desalination as a supply method of poor municipalities and families in social vulnerability. It became clear that the preservation of water resources for various actions, is hotly debated in today's society. We list a number of measures that deal with the reuse of water, water conservation techniques or strategies and equipment that allow fresh water extraction of the oceans. We found that desalination is a widely studied solution by enabling the treatment of brackish water or brine, enabling the production of potable water. Identified the existence and development of equipment operating at any scale, costs, benefits and environmental impacts vary according to the used technique. We performed the comparison between reverse osmosis, a method that is used extensively by many countries, and the capacitive deionization, which is in growing phase of research in worldwide. We proved that it is necessary to enlarge the studies about the capacitive deionization to enable the development of facilities to allow desalinate water and promote the development of poor regions, the health of these populations and families, democratizing access to water.

KEYWORDS: Water desalination. Capacitive deionization. Reverse osmosis.

\section{RESUMEN}

En este artículo se aclarará la importancia de la desalinización del agua como método de suministro de municipios pobres y familias en vulnerabilidad social. Se hizo evidente que la preservación de los recursos hídricos para diversas acciones, se discute caliente en la sociedad actual. Tenemos una lista de una serie de medidas que tienen que ver con la reutilización del agua, técnicas de conservación del agua o estrategias y equipos que permiten la extracción de agua dulce de los océanos. Se encontró que la desalación es una solución ampliamente estudiada, permitiendo el tratamiento de agua salobre y salina para la producción de agua potable. Identificar la existencia y desarrollo de equipos de funcionamiento a cualquier escala, costos, beneficios e impactos ambientales varían en función de la técnica utilizada. Se realizó la comparación entre la ósmosis inversa, un método que se utiliza ampliamente en muchos países, y la desionización capacitiva, que está en fase de crecimiento de la investigación en todo el mundo. Pudimos comprobar que existe la necesidad de amplificación de los estudios sobre la desionización capacitiva para permitir el desarrollo de instalaciones para permitir que el agua a desalinizar para promover el desarrollo de las regiones pobres, la salud de estas poblaciones y famílias, en proceso de democratización del acceso al agua.

PALABRAS CLAVE: Desalinización del agua. Desionización capacitiva. Ósmosis inversa. 


\section{INTRODUÇÃO E OBJETIVOS}

A agua é um recurso essencial ao desenvolvimento e manutenção da vida em nosso planeta, e cerca de $70 \%$ da superfície terrestre está coberto por esse mineral. Entretanto, a grande parcela desses recursos hídricos está sob forma de água salgada, nos mares e oceanos, imprópria para o consumo direto por nossa sociedade. O aumento da população nas últimas décadas e a falta de estratégias de conservação e uso dos recursos hídricos disponíveis, propiciaram alterações drásticas no ciclo hidrológico natural do planeta reduzindo a quantidade de água doce disponibilizada. (BRAGA, 2005).

A quantidade aproximada de água na Terra é de 1,386 bilhões de $\mathrm{km}^{3}$. Sendo $97,5 \%$ desse total representados por águas salgadas dos mares e oceanos e só $2,5 \%$ são água doce. Dessa parcela de água doce, cerca de $68,7 \%$ está retida na calotas polares e geleiras; e sob forma de vapor. Apenas $0,27 \%$ da parcela de água doce se encontra nos lagos, rios e reservatórios. Em suma, apenas $0,007 \%$ de todo volume hídrico de nosso planeta é de água doce localizada em locais de acesso fácil para a população (BÓS, 2012).

A falta de políticas públicas para a gestão dos recursos hídricos, de estratégias para o reúso de água e a ausência na adoção de técnicas que permitam a utilização de maneira mais correta possível dos recursos hídricos disponíveis forma fatores preponderantes à recente crise hídrica que assolou o Estado de São Paulo. A água é primordial no processo de produção de alimentos, sua falta irá implicar em risco de sobrevivência para as populações (GARCIA et al., 2015; GABRIEL et al., 2015).

A salinização de águas localizadas em regiões mais secas é frequente. Solos irrigados se tornam improdutivos por conta do uso de águas ruins na irrigação. Os índices de salinidade para a água usada variam conforma a modalidade de cultivo, o solo e os fatores climáticos da região. $O$ uso de águas com concentrações salinas acima de $2 \mathrm{~kg} / \mathrm{m}^{3}$ culminam no déficit da produtividade agrícola de diversas culturas (SOUZA, 2006).

A baixa quantidade de água doce disponível para o consumo humano em diversas regiões do planeta tem incentivado pesquisas sobre alternativas eficientes e eficazes que possibilitem a obtenção desse mineral essencial à vida. Diversas propostas são elaboradas para tentar amenizar o problema, entre elas a dessalinização recebe muitas menções.

Dessalinização consiste em uma série de processos químicos que propiciam a remoção dos sais tornando a água potável e doce podendo ser utilizada para as mais diversas finalidades, inclusive utilização doméstica e para manutenção das necessidades fisiológicas dos seres humanos.

A dessalinização da água do mar tem se tornado uma alternativa bastante eficiente em diversos países. Várias são as tecnologias empregadas para as mais diversas finalidades de utilização. $O$ processo de captação de água doce das formas tradicionais se torna mais caro à medida que a quantidade disponível se reduz e em contrapartida o processo da retirada de sal se tornou mais barato por conta do desenvolvimento de tecnologias novas para os processos (GOMES FILHO et al., 2014).

De acordo com CONAMA (2005), a água caracterizada como doce possui concentração de sais igual ou inferior a $500 \mathrm{mg} / \mathrm{l}$, salobras superior a $501 \mathrm{mg} / \mathrm{l}$ e inferior a $30 \mathrm{mg} / \mathrm{l}$; e as águas salinas possuem concentrações de sais superiores a $30 \mathrm{mg} / \mathrm{l}$.

As técnicas de tornar água do mar própria para o consumo tem sido uma grande busca das sociedades ao longo da história. A maior parte do planeta é coberta por água salgada que é majoritariamente utilizada apenas como meio de transporte e obtenção de pescados, pois o teor de sal é muito elevado para consumo humano. Os tipos de clima, solo, característica 
geológicas e distância dos oceanos determinam o grau de salinidade das águas em nosso planeta (SOUZA, 2006).

A coleta do vapor obtido do aquecimento de água salgada e o posterior resfriamento objetivando a obtenção de água doce e potável vem de longa data, além de ser um processo que também acontece naturalmente através do ciclo hidrológico de nosso planeta. As técnicas para separar o sal da água datam da época em que o sal era o bem precioso e precisaria ser extraído da água. Apenas após o aumento de demanda de água por parte da população, começou-se a pesquisar métodos que possibilitassem produzir água doce em locais secos e em navios de guerra (COOLEY et al., 2006).

Dois tipos de processos para dessalinização de água do mar são largamente utilizados em plataformas petrolíferas, a destilação à vácuo e a osmose reversa. O primeiro método gera um vácuo no compartimento em que a água salgada está armazenada reduzindo o ponto de ebulição da mistura e o segundo possibilita que a água marítima passe por canais com membranas que retém o sal (GOMES FILHO et al., 2014).

A dessalinização térmica (DT) é um dos recursos mais antigos para separar extrair os sais presentes na água, replicando parcialmente o ciclo hidrológico natural. A dessalinização por congelamento (DC) vêm sendo estudado como uma possível alternativa futura de extração em grande escala (SOUZA \& FERREIRA, 2016).

Atualmente, os principais métodos existentes para dessalinização são a osmose reversa (OR) e a destilação flash em multiestágios (DFE). No entanto, os métodos citados têm em comum o fato de necessitarem de grande consumo de energia e apresentar dificuldades na manutenção. Assim, urge a necessidade do desenvolvimento de tecnologias e métodos que consumam pouca energia e sejam de fácil manutenção para possibilitar a utilização em largas escalas (ZORNITTA, 2015).

A deionização capacitiva (DIC), que começou a ser estudada por volta de 1960, é provavelmente a alternativa mais viável para os entraves apresentados nos demais métodos. Utilizando baixos potenciais elétricos na retirada de íons de águas salobras é uma tecnologia com baixo consumo de energia e de fácil manutenção (JIA \& ZHANG, 2016).

\subsection{Osmose reversa (OR)}

Nos dias atuais são utilizadas, pelas estações de dessalinização, membranas osmóticas sintéticas de diversas composições em conjunto com diversas tecnologias inovadoras para o processo. $\mathrm{O}$ fenômeno da osmose ocorre quando um liquido passa de um meio onde há menor concentração de solutos para onde é mais elevada essa concentração (SILVA, 2016).

No caso da OR, o líquido concentrado, representando pela agua salgada, é forçado por uma elevada pressão a atravessar os poros de uma membrana semipermeável, geralmente composta por polímeros orgânicos, que irá filtrar e reter os sais liberando apenas a água doce para um tanque de armazenamento. Do outro lado, sobra uma água extremamente concentrada em sais que pode ser colocada para evaporação e produzir sal possível de comercialização. O método recebe essa denominação, pois o fenômeno natural da osmose consistiria na água doce atravessar espontaneamente a membrana em direção à água salgada. O funcionamento da OR é demonstrado na Figura 1 (BAIRD \& CANN, 2008). 


\section{da Alta Paulista}

Figura 1: Funcionamento da OR

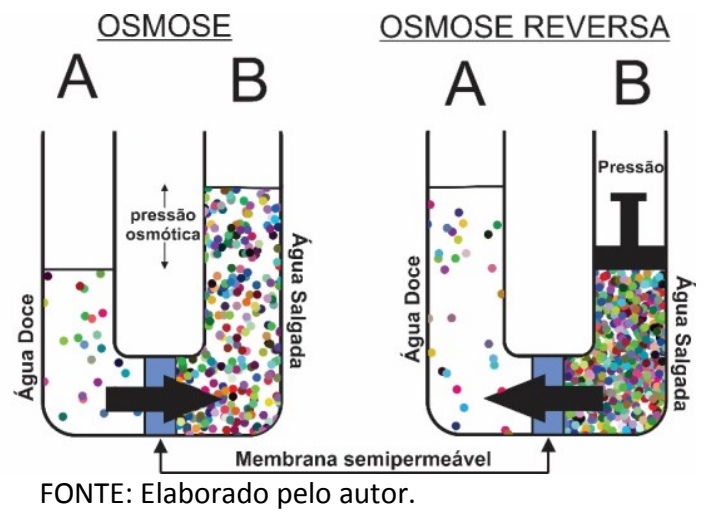

\subsection{Destilação multiestágios (DFE)}

Com água salgada em concentrações muita elevadas, a técnica de destilação é mais eficiente e consiste em proporcionar o aquecimento do liquido para que a água evapore, tudo isso em um ambiente fechado, e o vapor d'água será condensando e coletado sob forma de água doce (BAIRD \& CANN, 2008).

A DFE, como o nome já indica, se utiliza de vapor d'água em altas temperaturas para conseguir que a água salgada entre em processo de ebulição. Esse processo ocorre por diversos compartimentos que possibilitam sucessivas ebulições e condensações da água em tratamento por utilizar temperaturas e pressões diversas em cada etapa. A própria água do mar pode ser utilizada para propiciar a condensação durante o processo e a pressão dos compartimentos, onde o processo ocorre, é regulada de forma a reduzir o ponto de ebulição da água salgada, possibilitando menos gasto de energia para a evaporação da mesma. A Figura 2 demonstra 0 funcionamento da DEF (CUNHA \& FERREIRA, 2014).

Figura 2: Modelo da DFE

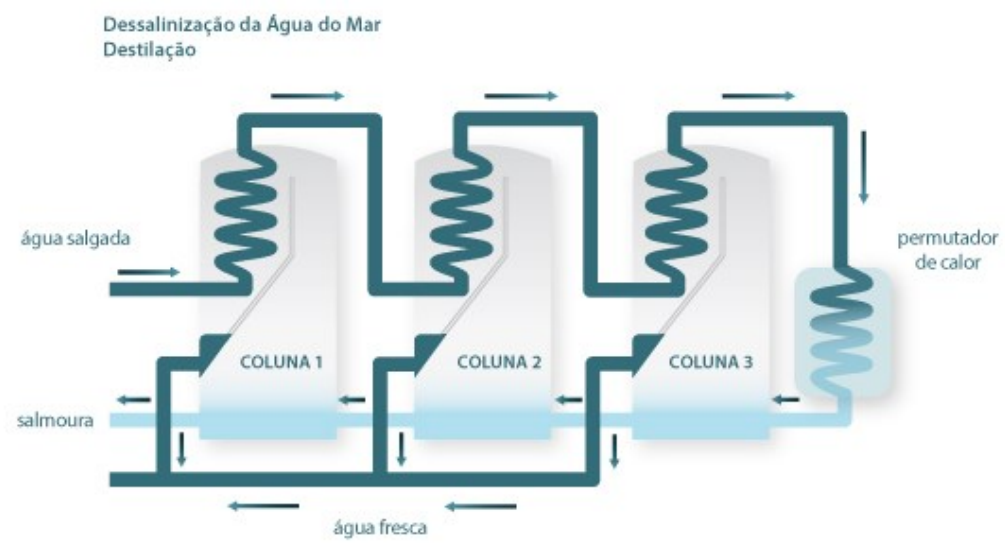

FONTE: PORTAL, 2016. 


\subsection{Dessalinização térmica (DT)}

Um dos processos mais antigos, a dessalinização térmica se vale de replicar o ciclo hidrológico natural. A forma mais utilizada é a destilação realizada em grandes tanques com coberturas de vidro ou outro material com índice de transparência elevada. A luz do Sol, ao atravessar a cobertura dos tanques, transfere a energia solar para a água provocando seu aquecimento até que chegue ao processo de ebulição e evaporação, formando vapor d'água, que irá se condensar ao entrar em contato com a cobertura do tanque. Ao se condensar, o vapor d'água irá se transformar em líquido e será recolhido por diversos coletores, possibilitando assim, que ao final do processo haja êxito na retirada de água doce de um composto Inicial de água salgada (SOUZA \& FERREIRA, 2016).

Diversas formas de energia podem ser utilizadas para se obter o aquecimento inicial do processo, porém a energia solar tem custo menor além de ser ecologicamente viável (SOUZA \& FERREIRA, 2016).

\subsection{Dessalinização por congelamento (DC)}

A dessalinização por congelamento, baseado no que ocorre naturalmente e pode ser observado nas geleiras, consiste em congelar a água salgada, provocando o aparecimento de água doce em estado sólido (gelo) que pode ser separada, a partir daí, e posteriormente descongelada, produzindo apenas a água doce. Apesar desse método ainda não ter sido realizado em larga escala, há muitos estudos que indicam a viabilidade da exploração da água doce contida nas calotas polares (CAO et al., 2015).

\subsection{Deionização capacitiva (DIC)}

A DIC, chamado também de eletrossorção, se caracteriza como uma tecnologia de dessalinização com crescentes pesquisas para seu aperfeiçoamento. Utiliza eletrodos porosos que atuam na remoção dos íons presentes na água salgada por um fenômeno chamado eletrossorção. Com funcionamento muito parecido ao de capacitores elétricos, a energia é armazenada e liberada durante a carga e descarga, ciclicamente. Atualmente, todos os projetos que usam DIC operam com tensões menores que 2 volts (HAN et al., 2015).

É uma tecnologia promissora, com excelente custo-benefício e praticidade na implementação para o tratamento de água salobra. $O$ desenvolvimento de novos materiais para a composição dos eletrodos é fundamental para melhor eficiência no processo de remoção dos sais. A polianilina é o polímero condutor mais pesquisado por conta das excelentes propriedades elétricas e estabilidade (JIA \& ZHANG, 2016).

\footnotetext{
Conforme a Associação de Geógrafos Brasileiros, em 2004 existiam aproximadamente 3000 sistemas de dessalinização por osmose reversa instalados na região semiárida do Nordeste. Porém, boa parte destes equipamentos não estava funcionando devido à falta de manutenção e ao seu mau uso. A dessalinização utilizando tecnologia de deionização capacitiva surge como uma alternativa simples e de baixo custo para a obtenção de água potável nestas regiões. (ZORNITTA \& RUOTOLO, 2014).
}

Conforme exibido na Figura 3, o processo ocorre em duas etapas cíclicas. No momento do carregamento é aplicada uma diferença de potencial elétrico que força os ânions e cátions, que são íons negativamente e positivamente carregados respectivamente, a se agruparem nas superfícies do eletrodo com carga oposta, cátodo e ânodo, e estes são removidos pela 
eletrossorção. No segundo estágio, do descarregamento, ocorre a regeneração dos eletrodos, através da interrupção ou reversão da corrente aplicada, e os íons são liberados na solução e a salmoura concentrada é liberada. São diversos ciclos de carga e descarga para a produção de água doce a partir de água salgada (VASCONCELOS, 2016; ZORNITTA \& RUOTOLO, 2014).

Figura 3: Funcionamento do DIC

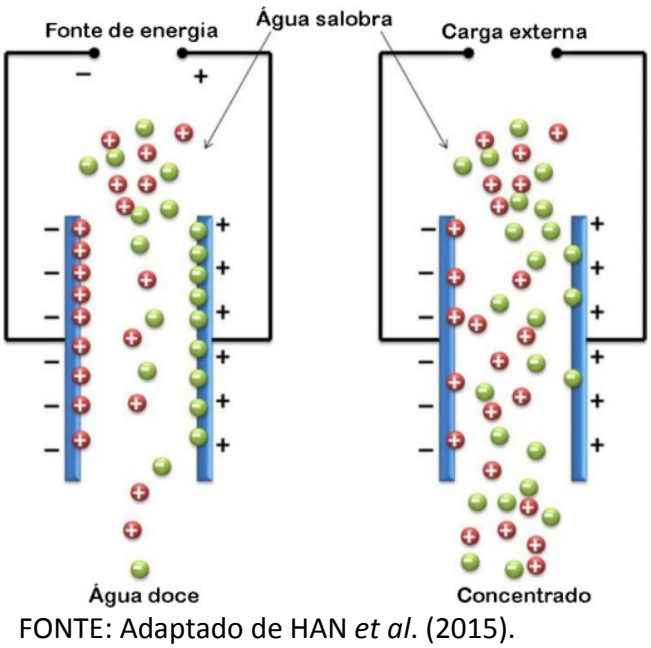

A DIC tradicional é ineficiente do ponto de vista energético, pois a adsorção e a dessorção dos íons ocorrem ao mesmo tempo na dupla camada elétrica gerada. Ao ser aplicado uma diferença de potencial aos eletrodos, ocorre a expulsão de contra-íons e a atração de co-íons simultaneamente, o que reduz a eficiência da dessalinização. Para solucionar esse problema, foram desenvolvidas técnicas para a deionização capacitiva com membrana (DICM) (JIA \& ZHANG, 2016).

Nesse sentindo, Zornitta (2015) explica que:

Quando um potencial elétrico é aplicado, os contra- íons (íons que possuem carga oposta à do eletrodo) serão eletrossorvidos no eletrodo enquanto os co-íons (íons que possuem a mesma carga que o eletrodo) serão expelidos do mesmo. Isto significa que um outro processo de eletrossorção/dessorção ocorre simultaneamente no eletrodo, reduzindo seriamente a eficiência de dessalinização do mesmo. (ZORNITTA, 2015).

Em um estudo realizado por Zhao et al. (2013), os dados demonstraram o consumo de energia em relação à concentração de sal na água em experimentos de escala laboratorial, fizeram uma comparação desses com os dados de gasto energético de OR relatados na literatura atual para usinas de dessalinização em larga escala. Verificou que o método de dessalinização por DICM tem mais eficiência com concentrações salinas abaixo de 60 mM.

\subsection{A dessalinização no Brasil}

No Brasil, a grande maioria das iniciativas dos projetos de dessalinização da água se constituem em instalações de pequeno porte, porém isso não reduz os impactos de eventuais contaminações ambientais ocasionadas pelos rejeitos do processo (SOARES, 2006).

A descarga do rejeito salino gerado durante o processo de dessalinização pelas estações, se constitui no principal problema ambiental decorrente dos métodos atualmente empregados 
para esse processamento. Comumente, essa água residuária é descartada no meio aquático causando várias alterações no ecossistema de descarte, pois a salmoura é composta por vários produtos químicos em concentrações elevadas (ARAÚJO, 2013).

A qualidade inferior das condições dos poços e de águas subterrâneas, principalmente em regiões semiáridas, que são geralmente salinas e salobra, exige o uso de estratégias de dessalinização para tornarem a água própria ao consumo e ao desenvolvimento socioeconômico dessas localidades (SILVA, 2015).

Técnicas para a realização da dessalinização de água do mar em larga escala e com viabilidade de implementação são apontadas como solução para a maioria dos problemas de escassez de recursos hídricos no planeta. Dois tipos de água são utilizados no processo de dessalinização, a água do mar e a água salobra subterrânea (SILVA, 2015).

A água do mar e a água subterrânea salobra, presentes em poços e açudes, são encontradas em diversas áreas do semiárido nordestino brasileiro. É considerada salobra a água com concentração entre 0,5 e 30 gramas de sal por litro. Os longos períodos de seca acentuam a ocorrência das águas salobras (JESUS et al., 2015).

Dois tipos de água são resultantes das dessalinizações: a água purificada e a água residual. $\mathrm{A}$ água dita potável deve conter uma quantidade mínima de sais minerais, pois o consumo de água totalmente isenta de sais, como a água destilada pura, não é indicado por propiciar a retiradas dos sais minerais do corpo. Por conta disso, as águas dessalinizadas devem ter quantidades de sais minimamente suficientes para não afetar o equilíbrio das funções do corpo humano. As águas residuais, ou rejeitos salinos, com alto teor salino tem sido utilizada em diversos tipos de atividades agrícolas (JESUS et al., 2015).

Cumpre observar também que a ingestão de águas salobras pode ocasionar problemas ligados à hipertensão arterial, que já atingem cerca de $30 \%$ dos brasileiros. No mundo, os fatores advindos da hipertensão são responsáveis pela morte de aproximadamente 9,4 milhões de pessoas ao ano. $\mathrm{O}$ consumo de sódio em excesso, mais de $2 \mathrm{~g}$ ao dia, ocasiona o aumento da pressão arterial, podendo desencadear diversas doenças cardíacas e circulatórias fatais. (TEIXEIRA et al., 2016; LOURENÇO \& MACEDO, 2015).

Carvalho et al. (2014) efetuaram uma pesquisa sobre a utilização de dessalinizadores em águas salobras provenientes de poços artesianos na geração de água pura para irrigar culturas de milho verde. Observou que o solo não sofreu contaminação, a produtividade do milho aumentou por conta de ter sido reduzida a presença de sais no solo, com isso os rendimentos dos agricultores também cresceram e criaram-se a possibilidade da realização de culturas diversas nas várias estações do ano.

\subsection{A utilização do rejeito salino}

O processo de dessalinização é responsável por alguns problemas ambientais que podem ser causados pelo rejeito produzido durante a extração da água doce, pensando nisso Matos et al. (2015) realizaram um estudo que consistiu no cultivo da microalga Chlorella $s p$ em base de concentrado de dessalinização e verificou que, o uso do rejeito da dessalinização, representou uma excelente opção para alimentação animal e complementos nutricionais por conta do alto teor proteico apresentado.

Dias et al. (2011) realizaram um estudo que buscava verificar o uso do rejeito da salinização em soluções nutritivas para produção hidropônica de alface (Lactuca sativa L.), utilizou a água salobra na composição da solução de nutrientes das plantas e constatou um leve prejuízo na produtividade de plantas comercialmente aceitáveis. Em uma pesquisa semelhante realizada 
por SANTOS et al. (2010) com a mesma cultura, a constatação foi de que a água salobra reduziu o crescimento e a produção da alface.

Em uma pesquisa que buscava analisar o plantio hidropônico de tomates, Cosme et al. (2011) adicionou ao composto de nutrientes fornecido às plantas água de rejeito da dessalinização. Constatou-se a redução significativa na produção da cultura em estudo. No cultivo hidropônico do meloeiro, a água de rejeito da dessalinização foi utilizada e o resultado foi de perdas muito pequenas na produção dos frutos (DIAS et al., 2010).

\section{METODOLOGIA}

Através de uma extensiva revisão bibliográfica em vários trabalhos brasileiros e internacionais sobre a temática, identificamos todas as informações necessárias ao embasamento do presente artigo de forma a contribuir para o atingimento dos objetivos elencados.

Localizamos artigos científicos e livros onde houvesse informações que constituiriam os alicerces do presente estudo. Após, identificamos teses, dissertações e dados de organismos internacionais disponibilizados na internet como forma de enriquecer o conteúdo do estudo (LAKATOS \& MARCONI, 2010).

Utilizamos dados originários de diversas fontes oficiais disponibilizadas para a comprovação das informações apresentadas de modo a confirmar a necessidade da utilização de um método eficiente de dessalinização (PRODANOV, 2013).

A partir das discussões, vislumbramos perspectivas para a realização de novos estudos referentes à métodos eficientes para a dessalinização de água para o consumo humano levando em conta a eficiência energética, a redução nos impactos ambientais ocasionados com os rejeitos e a facilidade de implementação e manutenção da estação de dessalinização.

\section{ANÁLISE DE RESULTADOS}

Os métodos mais utilizados para dessalinização são o de DEF e OR. Por DEF, o gasto enérgico é o maior, cerca de $25 \mathrm{Wh} / \mathrm{L}$, perdida durante a fase de condensação. A OR tem um gasto enérgico mais eficiente que a DEF, são cerca de $5 \mathrm{Wh} / \mathrm{L}$. São utilizadas, na maioria das vezes, membranas feitas de poliamidas ou celulose, além de necessitar uma elevada pressão para a remoção do sal, o que implica na necessidade de uma infraestrutura com um custo alto. A DIC possui um gasto enérgico muito menor que as duas anteriores, cerca de $1,1 \mathrm{Wh} / \mathrm{L}$, podendo ser empregada em pequenas escalas proporcionando a utilização até mesmo em residências (METKE et al., 2016).

Em projetos de grande escala, destaca-se o aumento no consumo de energia, com valores que vão de 2,9 a 3,7 kWh por $\mathrm{m}^{3}$ de água doce dessalinizada. Esse consumo é fruto das altas pressões necessárias para que a água salgada atravesse a membrana semipermeável (ZORNITTA, 2015).

Embora a tecnologia de OR seja eficiente no abastecimento hídrico de alguns usuários industriais e domésticos com elevado poder aquisitivo, não é acessível à países mais pobres e moradores situados à grandes distâncias das estações de dessalinização. São diversos os avanços tecnológicos para a dessalinização de água, porém os rejeitos do concentrado salino são reconhecidamente prejudiciais aos ecossistemas marinhos onde são descartados (SILVA, 2015).

Diversos países, como Arábia Saudita, Kuwait e Emirados Árabes, dependem intensamente dos processos de dessalinização de água salina ou salobra para o abastecimento de sua população e setores produtivos (TORRI, 2015). 
Com a redução do custo da dessalinização da água, o número de estações dessalinizadoras aumentou consideravelmente em todo planeta. Em Fernando de Noronha, famoso arquipélago brasileiro, foi construída a maior estação de dessalinização do país. Essa estação já produz quase metade da água consumida pela população do conjunto de ilhas e está em elaboração um projeto para suprir, quase que na totalidade, a demanda por recursos hídricos da região. O fluxo de dessalinização passará dos atuais $27 \mathrm{~m}^{3} / \mathrm{h}$ para $60 \mathrm{~m}^{3} / \mathrm{h}$, acabando com os problemas de escassez de água no arquipélago (TORRI, 2015).

Muitos aparelhos para dessalinização de água salobra através da OR foram comprados por brasileiros, principalmente no nordeste do país, por conta das intensas crises hídricas que assolam a região indefinidamente. Para os moradores da região, a dessalinização das águas é a única opção para terem acesso a esse mineral necessário à manutenção da vida. A ressalva na utilização do método se constitui no fato do processo de dessalinização por osmose gerar um rejeito, uma água residuária altamente salgada e por isso poluente (SOARES, 2006).

\section{CONSIDERAÇÔES FINAIS}

Diversos países no mundo, por estarem geograficamente localizados em regiões áridas e com pouco ou quase nenhum acesso a agua doce potável, adotam técnicas de dessalinização para o fornecimento hídrico à suas populações.

As regiões mais secas do Brasil vivem situação de extrema carência hídrica. A falta de água para o consumo humano e para a produção de alimentos afeta tanto as famílias quanto os agricultores e produtores rurais, em um efeito dominó que coloca em risco toda sociedade da região por conta de acarretar desequilíbrios econômicos e sociais afetando as comunidades em uma ampla gama de fatores.

Dessalinizar água requer cuidados e monitoramento da qualidade de água doce produzida. Se for ingerida água dessalinizada fora dos parâmetros recomendados, com excesso de sal ou a carência desse, o funcionamento do organismo humano pode ser afetado e acarretar doenças. A utilização das tecnologias baseadas em OR, apesar de serem eficientes, são caras e ocasionam os rejeitos salinos de alto impacto ambiental. São largamente utilizadas por países do oriente médio e, até mesmo no Brasil, há experiências em larga escala com uso de equipamentos que operam por OR.

Surgem como esperança para as comunidades pobres e municípios com poucos recursos, as pesquisas à cerca de técnicas para a dessalinização com uso de DIC, que se mostra bem mais eficiente para o tratamento de águas salobras. Está em pleno desenvolvimento a elaboração de diversos equipamentos que possibilitam aumentar a eficiência da dessalinização, ao mesmo tempo em que reduzem os custos e impactos ambientais.

Há necessidade da intensificação de pesquisas sobre os melhores materiais para os eletrodos utilizados nos dispositivos que utilizam DIC, como também arquiteturas e funcionamentos que possibilitem a criação e replicação de estruturas acessíveis à toda população, principalmente às famílias de maior vulnerabilidade social.

\section{REFERÊNCIAS BIBLIOGRÁFICAS}

ARAÚJO, Ana Carolina Silvério Pires de Abreu. Contribuição para o Estudo da Viabilidade/Sustentabilidade da Dessalinização enquanto Técnica de Tratamento de Água. 2013. Dissertação (Mestrado em Engenharia do Ambiente) - Faculdade de Ciências e Tecnologia - Universidade Nova de Lisboa, 2013. Disponível em: < http://run.unl.pt/bitstream/10362/10203/1/Araujo_2013.pdf>. Acessado em: 1 mar. 2016.

BAIRD, Colin; CANN, Michael. Environmental chemistry. 4. ed. New York: W. H. Freeman and Company, 2008. 
BÓS, Sidiane Manfron; THOMÉ, Antônio. Métodos para Avaliar Vulnerabilidade das Águas Subterrâneas. 1ạ edição. Porto Alegre: Poa Comunicação, 2012, 82p.

BRAGA, Benedito et al. Introdução à engenharia ambiental: o desafio do desenvolvimento sustentável. 2. ed. São Paulo: Pearson Prentice Hall, 2005.

CAO, Wensheng; BEGGS, Clive; MUJTABA, Igbal M. Theoretical approach of freeze seawater desalination on flake ice maker utilizing LNG cold energy. Desalination. n. 355, p. 22-32, 2015. Disponível em: < https://bradscholars.brad.ac.uk/bitstream/handle/10454/7944/mujtaba_theoretical_approach.pdf>. Acessado em: 25 mar. 2016.

CARVALHO, Lucas Santos et al. Utilização de água salobra produzida por poço artesiano na plantação de milho verde (ZEA MAYS). Cadernos de Graduação - Ciências Exatas e Tecnológicas Unit. Aracaju, v. 2, n.1, p. 45-54, 2014. Disponível em: < https://periodicos.set.edu.br/index.php/cadernoexatas/article/view/895/724>. Acessado em: 4 mar. 2016.

CONSELHO NACIONAL DO MEIO AMBIENTE (CONAMA). Resolução CONAMA n.357, de 17 de março de 2005. Brasília. Disponível em: < http://www.mma.gov.br/port/conama/res/res05/res35705.pdf>. Acessado em: 6 abr. 2016.

COOLEY, Heather; GLEICK, Peter H.; WOLF, Gary. Desalination, with a grain of salt - A California Perspective. Pacific Institute for Studies in Development, Environment and Security. Oakland, 2006, 100p. Disponível em: <http://pacinst.org/wp-content/uploads/sites/21/2015/01/desalination-grain-of-salt.pdf1>. Acessado em: 6 mar. 2016.

COSME, Christiano. R. et al. Produção de tomate hidropônico utilizando rejeito da dessalinização na solução nutritiva aplicados em diferentes épocas. Revista Brasileira de Engenharia Agrícola e Ambiental, v.15, n.5, p. 499504, 2011 Campina Grande, PB, UAEA/UFCG. Disponível em: http://www.scielo.br/pdf/rbeaa/v15n5/v15n5a10.pdf>. Acessado em: 4 mar. 2016.

CUNHA, Talita Mitsue Onose Araújo; FERREIRA, Eduardo Manfredini. Análise de critérios de produtividade de unidades de destilação flash - MSF. In: ENEPEX - Encontro de Ensino, Pesquisa e Extensão, UFGD, 2014.

DIAS, Nildo da Silva et al. Produção de melão rendilhado em sistema hidropônico com rejeito da dessalinização de água em solução nutritiva. Rev. Bras. Eng. Agrícola e Ambiental , v.14, n.7, p.755-761, 2010. Disponível em: <http://www.scielo.br/pdf/rbeaa/v14n7/a11v14n7.pdf>. Acessado em: 6 mar. 2016.

DIAS, Nildo da Silva et. al. Uso de rejeito da dessalinização na solução nutritiva da alface, cultivada em fibra de coco. Rev. Ceres, Viçosa, v. 58, n.5, p. 632-637, 2011. Disponível em: < http://www.redalyc.org/articulo.oa?id=305226809014>. Acessado em: 1 abr. 2016.

GABRIEL, Camila Pires Cremasco; CAVALCA, Diego Luiz; SALES, Luiz Fernandes da Silva. Sistema de automação de irrigação do plantio. In: XI Fórum Ambiental da Alta Paulista, v. 11, n. 6, p. 250-257, 2015.

GARCIA, Érica Natasha dos Anjos; MORENO, Diego Aparecido Alves Costa; FERNANDES, André Luís Valverde. A importância da preservação e conservação das águas superficiais e subterrâneas: um panorama sobre a escassez da água no Brasil. In: XI Fórum Ambiental da Alta Paulista, v. 11, n. 6, p. 235-249, 2015.

GOMES FILHO, Hélio Ribeiro; ROCHA, Edêmea Faria Carlos da; OLIVEIRA, Vicente de Paulo Santos de. Produção e consumo de água dessalinizada em plataforma de petróleo. Boletim do Obs, Amb. Alberto Ribeiro Lamego, Campos dos Goytacazes/RJ, v.8 n.2, p. 9-17, $2014 . \quad$ Disponível em: <http://www.essentiaeditora.iff.edu.br/index.php/boletim/article/view/2177-4560.v8n214-01/4315>. Acessado em: 7 mar. 2016.

HAN, Linchen; KARTHIKEYAN, K. G.; GREGORY, Kelvin. B. Energy Consumption and Recovery in Capacitive Deionization Using Nanoporous Activated Carbon Electrodes. Journal of The Electrochemical Society, v. 162, n. 12, p. E282-E288, 2015. Disponível em: < http://jes.ecsdl.org/content/162/12/E282.short> 
JESUS, Gabriel O. et al. Destilação de água por energia solar. Cadernos de Prospecção, Salvador, v. 8, n. 3, p. 469477, 2015. Disponível em: <http://www.portalseer.ufba.br/index.php/nit/article/view/11540/pdf>

JIA, Baoping; ZHANG, Wei. "Preparation and Application of Electrodes in Capacitive Deionization (CDI): A State-ofArt Review. " Nanoscale Research Letters, n. 11, p. 64. PMC, 2016. Disponível em: <http://www.ncbi.nIm.nih.gov/pmc/articles/PMC4740477/>. Acessado em: 1 mai. $2016 .$.

LAKATOS, Eva Maria; MARCONI, Marina de Andrade. Metodologia do trabalho científico: procedimentos básicos, pesquisa bibliográfica, projeto e relatório publicações e trabalhos científicos. 7. ed. São Paulo: Atlas, 2010.

LOURENÇO, André P.; MACEDO, Inês E. Consumo excessivo de sal na alimentação: um risco para além da hipertensão arterial? Rev. Port. Med. Geral e Familiar, Lisboa, v. 31, n. 3, p. 228-229, $2015 . \quad$ Disponível em: <http://www.scielo.mec.pt/scielo.php?script=sci_arttext\&pid=S2182-51732015000300011\&lng=pt\&nrm=iso>.

Acessado em: 01 mar. 2016.

MATOS, Ângelo Paggi et al. Teores de proteínas e lipídeos de Chlorella sp. cultivada em concentrado de dessalinização residual. Cienc. Rural, Santa Maria, v. 45, n. 2, p. 364-370, 2015. Disponível em: <http://dx.doi.org/10.1590/0103-8478cr20121104>. Acessado em: 1 fev. 2016.

METKE, Thomas et al. Particulate-Free Porous Silicon Networks for Efficient Capacitive Deionization Water Desalination. Scientific Reports, 6 (2016): 24680. PMC. Internet. Disponível em: <http://www.ncbi.nlm.nih.gov/pmc/articles/PMC4840374/>. Acessado em: 8 mai. 2016.

PORTAL LABORATÓRIOS VIRTUAIS DE PROCESSOS QUÍMICOS. Departamento de engenharia química - Universidade de Coimbra. Disponível em: <http://labvirtual.eq.uc.pt/>. Acessado em: 3 abr. 2016.

PRODANOV, Cleber Cristiano; FREITAS, Ernani Cesar de; Metodologia do Trabalho Científico: Métodos e Técnicas da Pesquisa e do Trabalho Acadêmico, 2. ed., Novo Hamburgo, 2013.

SANTOS, Rafaelly Suzanye da Silva et. al. Uso do rejeito da dessalinização de água salobra no cultivo da alface (Lactuca sativa L.) em sistema hidropônico NFT. Ciência e Agrotecnologia, v. 34, n. 4 Lavras, 2010. Disponível em: <http://dx.doi.org/10.1590/S1413-70542010000400026>. Acessado em: 1 mar. 2016.

SILVA, Martin Kássio Leme da. Qualidade da água no município de Lençóis Paulista-SP e Comparação entre métodos de purificação de água. TCC (Licenciatura - Química) - Universidade Estadual Paulista, Faculdade de Ciências, 2016. Disponível em: <http://hdl.handle.net/11449/136633>.

SILVA, Jefferson Fernandes do Amaral. Panorama global da distribuição e uso de água doce e análise de custos de uma planta de osmose reversa acionada com diferentes fontes de energia. 2015 . Dissertação (Mestrado em Sistemas de Gestão) - Universidade Federal Fluminense. Niterói, 2015.

SOARES, Tales M. Destinação de águas residuárias provenientes do processo de dessalinização por osmose reversa. R. Bras. Eng. Agríc. Ambiental, v.10, n.3, p.730-737, 2006. Disponível em: <http://www.scielo.br/pdf/rbeaa/v10n3/v10n3a28.pdf>. Acessado em: 27 mar. 2016.

SOUZA, Luiz Faustino. Dessalinização como fonte alternativa de água potável. Norte Científico, v.1, n.1, p. 84-97, 2006.

SOUZA, Luiz Enrique Vieira de; FERREIRA, Leila da Costa. Energias Renováveis e Segurança Hídrica: a energia termossolar como alternativa para a dessalinização da água do mar no Norte da África e Oriente Médio. In: Sustentabilidade em Debate, Brasília, v. 7, n. 1, p. 15-28, 2016. Disponível em: <http://www.gestaoesaude.unb.br/index.php/sust/article/view/15660/13386>. Acessado em: 3 mar. 2016.

TEIXEIRA, Juliana de Fátima et al. Conhecimento e atitudes sobre alimentos ricos em sódio por pacientes hipertensos. Arq. Bras. Cardiologia, São Paulo, 2016. Disponível em: < http://dx.doi.org/10.5935/abc.20160049 >. Acessado em: 01 mar. 2016. 
TORRI, Júlia Betina. Dessalinização de água salobra e/ou salgada: métodos, custos e aplicações. TCC (Engenharia Química) - Escola de Engenharia - Universidade Federal do Rio Grande do Sul, 2015. Disponível em: <http://hdl.handle.net/10183/127799>. Acessado em: 2 mar. 2016.

VASCONCELOS, Cláudia Karina Barbosa de. Modelos efetivos para separação solvente-soluto através de nanoestruturas: teoria e simulações computacionais. 2016. 83f. Tese (Doutorado em Engenharia de Materiais) Universidade Federal de Ouro Preto, Ouro Preto, 2016. Disponível em: http://www.repositorio.ufop.br/handle/123456789/6427>. Acessado em: 1 abr. 2016.

ZHAO, R.; PORADA, S., BIESHEUVEL, P.M.; VAN DER WAL, A. Energy consumption in membrane capacitive deionization for different water recoveries and flow rates, and comparison with reverse osmosis. Desalination, $n$. 330, p. 35-41, 2013. Disponível em: < http://dx.doi.org/10.1016/j.desal.2013.08.017>. Acessado em: 5 abr. 2016.

ZORNITTA, Rafael Linzmeyer; RUOTOLO, Luís Augusto Martins; Dessalinização de água utilizando tecnologia de deionização capacitiva: análise de diferentes eletrodos. In: Anais do XX Congresso Brasileiro de Engenharia Química, v.1, n.2, p. 15898-15905. São Paulo: Blucher, 2015.

ZORNITTA, Rafael Linzmeyer. Dessalinização usando tecnologia de deionização capacitiva. 117 f. Dissertação (Mestrado) - Universidade Federal de São Carlos, 2015. 